RESEÑAS 189

\title{
ROGER CHARTIER. Las revoluciones de la cultura
}

escrita. Barcelona, Gedisa, 2000, 183 pp.

\section{LA EVOLUCIÓN DE LA CULTURA ESCRITA EN LA LARGA DURACIÓN}

La escritura en la larga duración ha experimentado cambios tan importantes que han hecho de su evolución un campo fértil de estudio al que se han abocado diversas disciplinas. La historia no ha sido ajena a este ímpetu investigador que se ha desatado sobre las prácticas de la lectura y la escritura y, precisamente el libro aquí reseñado se sitúa en las producciones que sobre este tema se han realizado. Se trata de "Las revoluciones de la cultura escrita", de Roger Chartier, volumen en el que se reflexiona sobre las mutaciones que transformaron las técnicas de reproducción de los textos, las formas de los libros y las maneras de leer, a partir de diversas prácticas de la oralidad.

La obra se estructura en dos partes: Diálogo e Intervenciones. La primera parte, Diálogo, se trata de una entrevista con el periodista francés Jean Lebrun; mientras que la segunda, Intervenciones, recoge tres conferencias, un ensayo y dos entrevistas publicadas en revistas brasileñas, que se dirigen a lectores no profesionales de la historia. Sin embargo, pese a ser tan diverso, en el contenido del libro se pueden observar ciertos puntos de coincidencia a los cuales responde el análisis del autor: la evolución de la cultura escrita en la larga duración y los roles inherentes a ella.

En este sentido, el texto muestra cómo la escritura a través del tiempo ha conocido diversas revoluciones que han afectado no sólo la forma en que ésta se reproduce sino también los hábitos de lectura. Se trata, pues, de un recorrido por las diferentes evoluciones que ha experimentado la cultura escrita, desde el paso del rollo 
190 EL TALLER DE LA HISTORIA 2

(papiro o pergamino) al manuscrito, de éste al documento impreso con la revolución de Gutenberg a mediados de 1450, hasta la llegada del texto electrónico en el siglo XX. No obstante, se argumenta que la transición del manuscrito al texto impreso no señala una transformación absoluta, pues el libro manuscrito y el libro posterior a Gutenberg se basan en las mismas estructuras fundamentales: las del Codex. Igualmente, la distribución del texto en la superficie de la página, los instrumentos que permiten establecer referencias (paginación, foliación) y los diversos tipos de índices ya existen desde la época del manuscrito.

La verdadera ruptura con formas anteriores de la escritura y con prácticas de lectura la ubica Chartier en el nacimiento de la revolución electrónica, que incuestionablemente impone la necesidad de aprendizajes radicalmente nuevos, y por tanto la necesidad de tomar cierta distancia con hábitos ya adquiridos, lo cual, dice el autor, registra pocos precedentes en la cultura escrita. "El despliegue secuencial del texto en la pantalla, el hecho de que las fronteras del ordenador ya no sean radicalmente visibles como en el libro, la posibilidad que tiene el lector de mezclar, entrecruzar, reunir textos que están escritos en la misma memoria electrónica: todas estas características indican que la revolución del texto electrónico, es tanto una revolución de las estructuras del soporte material de lo escrito como de las maneras de leer" (p. 16).

Asimismo, Chartier muestra gran interés por definir los roles inherentes a la cultura escrita y por abordar los cambios acaecidos en ellos en la larga duración. Tales roles son: el autor, cuyo principal cambio estuvo en el tránsito de la vieja figura del "autor oral" (Platón, Aristóteles, Tito Livio, etc.), que emitía su discurso a través de la lección, el sermón o el teatro y no poseía vinculación directa con su obra redactada por escribas, a la del "autor moderno" que se apropia del texto a través de la redacción, proporcionándole una vinculación directa ligada a su nombre. La del editor, que evoluciona del editor-librero de los siglos XVI al XVIII que era principalmente un comerciante, a la del editor contemporáneo que es un intelectual cuya actividad se desarrolla también en un 
plano de igualdad al de los autores. Y en último lugar, Chartier se refiere al lector cuya actividad se define como una apropiación constante del texto, que deriva de las diferentes interpretaciones que se hacen de la lectura y usurpan la propuesta original que establece el autor.

En suma, el texto de Chartier traza los rasgos generales por los que ha pasado la evolución de lo escrito en el tiempo, determinando que los diversos cambios que se han generado con el advenimiento de las diversas revoluciones en la cultura escrita, lo que han otorgado es una libertad continua al autor y, sobre todo, al lector de hoy, que con el texto electrónico, es irrefrenable; es decir, la tesis central del autor o el enlace que une los diversos textos de esta compilación sería que la cultura escrita ha ido conquistando, cada vez más una libertad en formas, hábitos y contenidos que a veces raya en lo abstracto, por la descorporización de que ha sido objeto el texto con el ordenador, y en lo universal, por la gran difusión que tiene el conocimiento y la gran capacidad de interacción mundial que otorga la invención del texto electrónico. No obstante, a pesar de la gran ruptura que supone la invención del texto electrónico con hábitos anteriores de escritura y lectura, Chartier concluye que por más seductor que parezca el sueño de la universalidad y la interacción a distancia, ella no debe extraviarnos y no debe significar en modo alguno relegar, olvidar o destruir los manuscritos o libros que antes eran vehículos de la cultura escrita.

En términos generales, esta compilación es un buen instrumento para los que quieren enterarse de las diferentes mutaciones por las que ha pasado la cultura escrita en la larga duración y, de cierta manera, también es un acercamiento al estado en que se encuentra la historia del libro y un texto ayuda que proporciona buenas ideas sobre las cuestiones esenciales que se deben plantear todos aquellos que se interesan por el estudio del libro y las prácticas que lo acompañan.

Fabián del Campo Burgos. Programa de Historia Universidad de Cartagena 